\title{
Creating an Online Survey for Educational Institutions
}

\author{
S. K. Kezial Elizabeth ${ }^{1^{*}}$, K. Palraj ${ }^{2}$ \\ ${ }^{I}$ Student, Department of Computer Science and Engineering, Sri Vidya College of Engineering and Technology, \\ Virudhunagar, India \\ ${ }^{2}$ Professor \& HoD, Department of Computer Science and Engineering, Sri Vidya College of Engineering and \\ Technology, Virudhunagar, India \\ *Corresponding author: kezialcse@gmail.com
}

\begin{abstract}
In these days education has changed as an essential for everyone. There are many preschools, elementary, secondary, higher secondary schools, universities, arts and science colleges and many. Finding the best school or institution for their children is really very tough for parents in these days. Our work is to create a web application to create online survey, which contains questions and feedbacks about the schools and institutions. The survey questions are related to the attributes, and the behavior of educational institution on behalf of the quality of education, school environment, teaching methodologies, about the management and teachers. And we give authority to attend the survey for the peoples from various places i.e. the former students of various institutions and schools. Thus using our survey we are collecting the data about the schools and institutions, then the data will be handover to the analyst. And the analyst will process the data and make decisions about the institutions and schools. They will decide the ratings for the institutions and schools in Tamilnadu, India. Based on the ratings the parents and students can choose their schools and colleges.
\end{abstract}

Keywords: Enviroment, Institutions, Management, Methodologies.

\section{Introduction}

Some of the expectations of parents from schools are leads a Balanced Life. Indian education system provides very good academic knowledge but school teachers play an important part in motivating students to take part in extra-curricular activities, which help in practical learning and developing inter-personal skills. These skills are very important to deliver at professional level. According to the study the most important goal that Indian parents have for their children is that they build successful careers in their adult life. This is the ultimate goal for $51 \%$ of the Indian parents surveyed. Only Mexican parents are ahead of India in rating a successful career of the children as the ultimate goal with $52 \%$ vouching for it. Asked to ranked three most important goals that they wanted their child to achieve as an adult $51 \%$ of the Indian parents choose successful careers, while $49 \%$ choose happiness in life, $33 \%$ identified a healthy life style, 22\% wanted them to earn enough for a comfortable life and $17 \%$ rated fulfilling their children's potential as the ultimate goal.
Thus every parent will face the problem while searching a good school which helps for their children's carrier. So we are developing the survey which helps by giving better results based on their findings. Fundamentally, a survey is a method of gathering information from a sample of people, traditionally with the intention of generalizing the results to a larger population.

\section{A. Survey}

Survey provides a critical source of data and insights for nearly everyone engaged in the information economy, from businesses and the media to government and academics. There are four modes of survey data collection that are commonly used.

1. Face-to-face surveys

2. Telephone surveys

3. Self-administered paper and pencil surveys

4. Self-administered computer surveys (typically online)

While surveys vary widely in how they are conducted and used, there are a number of components that are common across nearly all surveys. Many of these common features have been studied in extensive detail by survey methodologists, psychologists, statisticians, and many other fields of research. A personal interview survey, also called as a face-to-face survey, is a survey method that is utilized when a specific target population is involved. The purpose of conducting a personal interview survey is to explore the responses of the people to gather more and deeper information. A telephone survey is one of the survey methods used in collecting data either from the general population or from a specific target population. Telephone numbers are utilized by trained interviewers to contact and gather information from possible respondents. A traditional survey administration method, the paper-and-pencil survey is ideal for respondents who are not computer literate or do not have an access to the Internet. An online survey is a questionnaire that the target audience can complete over the Internet. Online surveys are usually created as Web forms with a database to store the answers and statistical software to provide analytics. 


\section{B. Web development}

Web development is the work involved in developing a web site for the Internet (World Wide Web) or an intranet (a private network). Web development can range from developing a simple single static page of plain text to complex web-based internet applications (web apps), electronic businesses, and social network services Among web professionals, "web development" usually refers to the main non-design aspects of building websites: writing markup and coding] Web development may use content management systems to make content changes easier and available with basic technical skills.

\section{Survey Goal}

A goal is not a single learning objective. A goal is what we are going to do with the data we collect, and why. A good survey goal: Use a survey to determine which markets are a good fit for our existing products. So we can expand into those markets. In making appropriate and concise survey goals, the researcher should ask himself the following questions:

1. "What is the subject?"(E.g. product, role, experience, method, etc.)

2. "What do I want to know?"(E.g. satisfaction with the product, effectiveness of the- method, etc.)

3. "Who should I ask?"(E.g. customers, mothers, high school students, etc.)

4. "To whom/what should I compare it?" (For comparative surveys) (E.g. traditional method, existing product, etc.)

Having a good survey goal is a favorable start in conducting a survey. Due to its anonymous nature, surveys are perfect for privacy-seeking students, adults, or even teachers. These powerful tools give them the space to air out concerns while offering in-depth insights into their way of thinking characteristics even prestigious institutions like IITs, IIMs etc. can benefit from. It also enables a healthy dialogue with the students - clear signs of a system fostering good practices. On the education front, it helps improves the quality of education and courses being provided, enhances teaching methods and processes, and helps everyone understand the learning environment at large in a school/college.

\section{Modules Description}

\section{A. Choosing the participants for survey}

Conducting a survey may probably be the most important part of writing your dissertation, since this is where we can get hard data to support our study. It might be the most challenging part as well, especially when we need to get as many respondents as possible to support your results. We may have everything down pat, from the objectives to the survey design, but without our respondents, our survey won't be as useful as we thought it might be. Conducting a survey doesn't just mean asking several random people to answer your questions - to save time, resources, and energy; you must first identify the respondents that represent your study's target demographic. Knowing who your respondents should be will help you determine where, when, and how you can reach them. Not only will you get the right respondents for your survey, but you'll also generate more useful insights from them. The participant that is the respondent of our survey is the people from various people in Tamilnadu, India. Most of our respondents are the social media users, and some are got to be attended because of the sharing's of the link or website that we developed. And we have given the authentication to the respondent for attending the survey. We have given them the user id and password for our responders to attend the survey.

\section{B. Survey Functionality}

The functions involves, after the authentication process there is some personal information questions thus to customize the survey questions for the respondents on behalf of their interest.

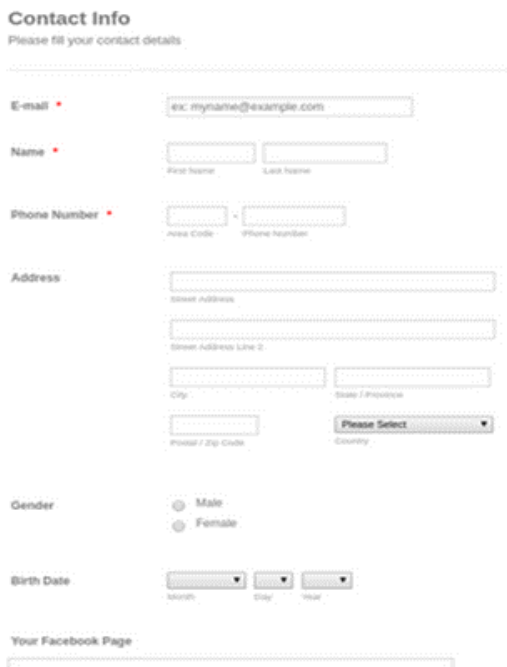

Fig.1. Personal detail form of survey respondent

After getting the details of the respondent the control will be passes to the survey questions form. And the personal data got from the respondent will be saved. The questions are about their schools such as about the name of the school and Institutions. In the personal information section the question will be asked about their educational qualification. Another good quality control technique is to have a question in which you say in the question text or in the label for a row in a grid that people should pick a particular answer. You can then discount any surveys that do not pick that answer. Alternatively, you can take people out of the survey if they submit the page without picking the specified answer choice. If you do so, make sure you prevent people backing up to that page.

\section{Survey Questionnaires}

The survey questions form contains that about the respondent's school experience which they got from their school. The survey questions types are the multiple choice questions, yes or no type's questions, and tell in few words types questions. Questions are asked like does your school encourages in your studies and other curricular activities. The 
questionnaires about,

- The quality of education they preserve in school/university.

- The care they show to the student's behavior and in mental improvement.

- About the security and the school/institution environment, which they really helps you to make a peaceful situation for study.

- Did they help you to build up your confidence, creativity and potentiality?

- The methodology teaching which they possess.

- Did they allow you to pay more interest in physical activities?

- About the teachers and management.

These are some of the aspects that we considered while taking the survey questions.

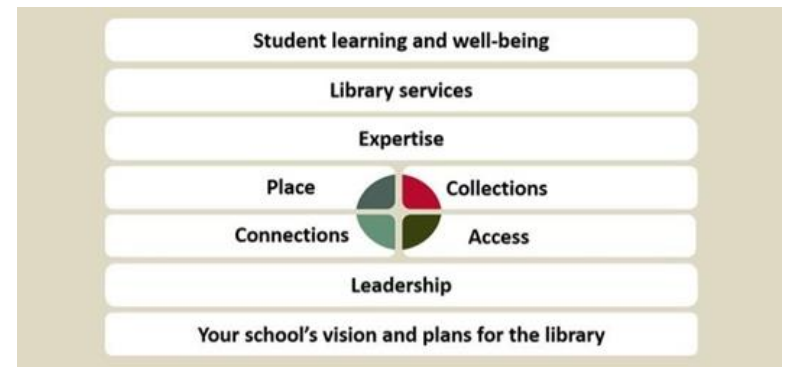

Fig. 2. Aspects considered for questionnaires

D. Model Questions

Questions about the quality of teaching,

1. How well do the professors/teachers teach at this university/school?

2. Are the lecturers proficient enough?

3. How effectively is this course/class/subject taught?

4. How much value are you getting from the course content overall?

5. Which is your favorite course/subject, and why?

6. How relevant is the curriculum to your field of study?

7. Do you feel job-competent moving forward from this university?

8. How would you rate the following aspects of your educational experience:

a. Quality of the teaching faculty

b. Course availability

c. Academic advising

d. Access to teaching faculty

e. Fellow students' academic ability

f. The academic reputation of the school

g. Value of education for the price

Questions about the learning environment

1. How helpful is your academic advisor?

2. How safe do you feel on campus?

3. How satisfied are you with the diversity and quality of the offered extracurricular activities?

4. How helpful are the campus staff with administrative and other issues?

5. How would you rate the following aspects of student life at the school:

- Sport and recreational facilities

- Clubs and student organizations

- Student diversity

- Campus safety

- Extracurricular activities

- Student safety

- Social life

Questions about facilities,

1. How well-maintained are the facilities?

2. How satisfied are you with the dormitory facilities?

3. How pleased are you with the quality of the food served at the school cafeteria?

4. How easy it is to get the resources you need from the school/university library?

5. How would you rate the following services/facilities at the school:

- Campus

- Class and laboratory facilities

- Library

- Parking

- Public transportation

- Student residences

- Food services

- $\quad$ Sports and fitness facilities

- Career counseling and placement

Other questions

1. What is your class year?

2. How satisfied are you with the school policies?

3. How satisfied are you with the overall experience studying here?

4. Which areas could use improvement regarding your experience at this institution?

5. How likely are you to continue attending this school/university next school year?

\section{Result and Implementation}

Based on the survey goals or the purpose of conducting the survey, choose the participants that will be able to effectively represent the general population. In this step of the planning phase, you should be able to determine the inclusion and exclusion criteria so only the right people can be included in the target group. Before you choose you need to point out the characteristics of people who belong to your target population. Literacy levels, language issues, geographic restrictions must be analyzed first. After the questionnaires set the survey is ready to launch. And the backend connection has to be 
established for collecting the respondent's data.

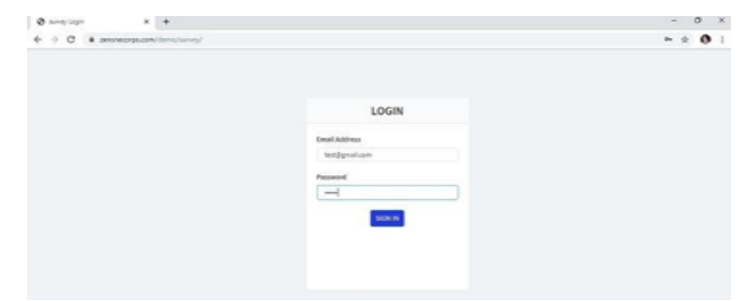

Fig. 3. Login page

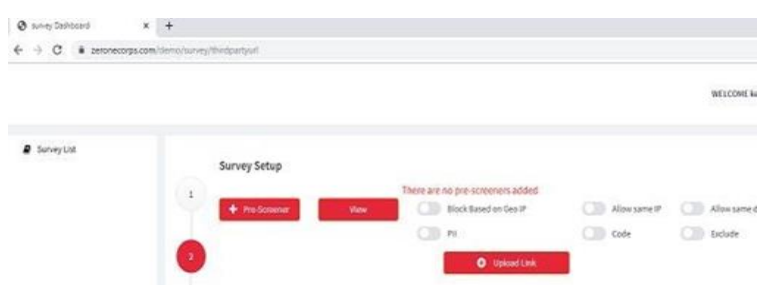

Fig. 4. Survey setup page

This page is to pre-screener for the questions making. And there is option for selecting the participants of the survey.

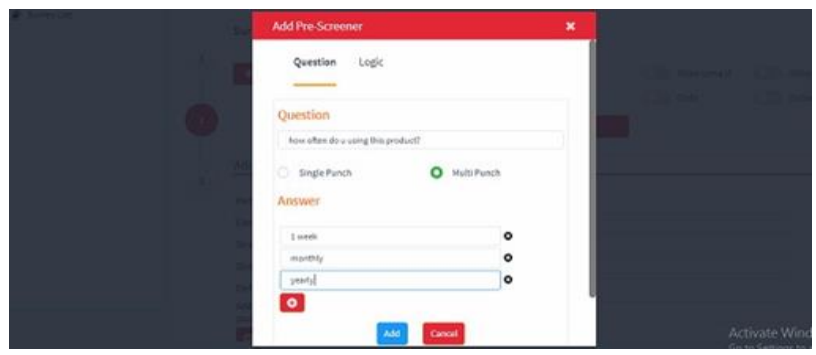

Fig. 5. Pre-screener setup

The pre screener page for questions making and its answers setting has shown above.

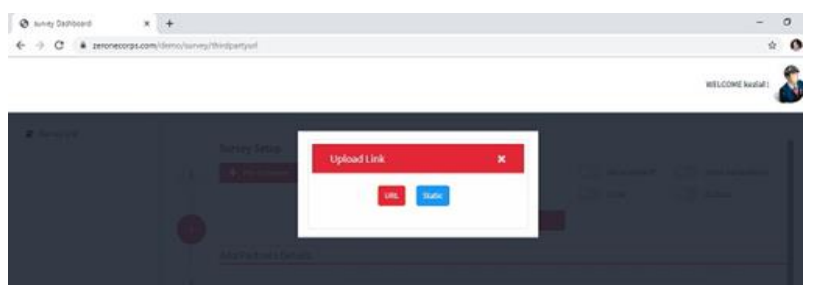

Fig. 6. Link setup

In the above page we can see that the url type specified. We have to create a url for the survey using static.

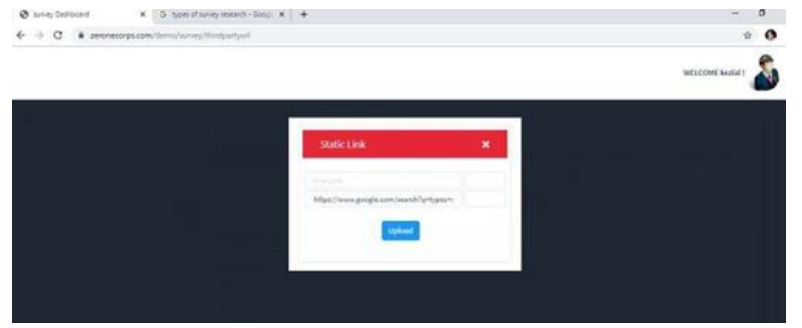

Fig. 7. Static link generation
In this page we have to give the demo URL for the survey URL. After launching the url we have to add the partner details who are going to promote the survey and thus to help the developer. In this quota setup we have to set the quota for the partner and for overall survey. Then we have to launch the survey.

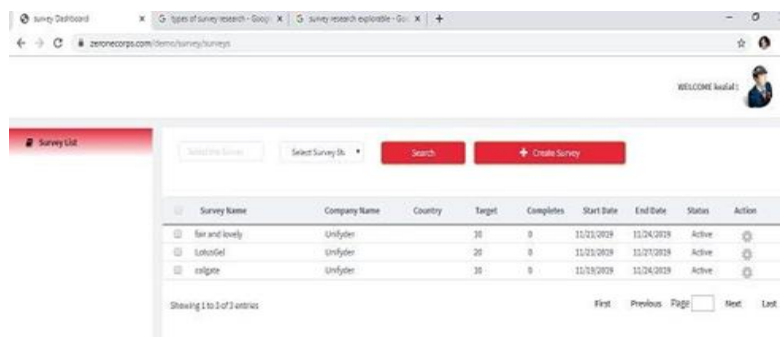

Fig. 8. Survey launch

There are some options for adding the partner details. We have to define the details of the partner who is going to help us in survey the product. We have to generate static URL for the survey. The details of partner and the quota of the survey also have to be described.

Then we can launch the survey.

\section{Conclusion}

Various papers related to this study were surveyed and few good solutions to our current problems were predicted. All methodologies, techniques were studied and compared with each other to find the effective methodology to overcome the existing problems. From this article, we came to know that the proposed method enhances the solution for creating a survey. Hence we have created an online survey for school and educational institutions, which terms to give suggestion for selecting the appropriate next grade are level school/institutions to provide better education for their children. The suggestions will be derived from the analysis.

\section{References}

[1] Christian Marxt, Dragana Popovie, Strategic aspects in collaborative product design: results of a survey in Swiss industry," IEEE, 2018.

[2] J. Sanjay L, B. M. Deshpande and S. Punnekkat, "An industrial survey on the influence of process and product attributes on software product reliability," 2017 International Conference on Networks \& Advances in Computational Technologies (NetACT), Thiruvanthapuram, 2017, pp. 44-51.

[3] A. Cordos, C. Drugan and S. D. Bolboacă, "Social media and healthrelated information: Surveys development and validation," 2017 E-Health and Bioengineering Conference (EHB), Sinaia, 2017, pp. 61-64.

[4] Amin Kharraz; William Robertson; Engin Kirda, "Surveylance: Automatically Detecting Online Survey Scams", IEEE, 2018.

[5] S. Elmidaoui, L. Cheikhi and A. Idri, "A survey of empirical studies in software product maintainability prediction models," 2016 11th International Conference on Intelligent Systems: Theories and Applications (SITA), Mohammedia, 2016, pp. 1-6.

[6] Y. Yan, Z. He, G. Liu, Y. Wang and C. Han, "The National Entironmental and Geological Information System for Remote Sensing Survey and Monitoring," 2015 IEEE International Geoscience and Remote Sensing Symposium (IGARSS), Milan, 2015, pp. 4700-4703. 
[7] H. Zhu, S. Wu, G. Zou and N. Luo, "Effective User Recommendation Model for Online Survey via BP Neural Network," 2015 IEEE 12th Intl Conf on Ubiquitous Intelligence and Computing and 2015 IEEE 12th Intl Conf on Autonomic and Trusted Computing and 2015 IEEE 15th Intl Conf on Scalable Computing and Communications and Its Associated Workshops (UIC-ATC-ScalCom), Beijing, 2015, pp. 1798-1802.

[8] Zhang Fusong, Diano Zhaofong, "Application of Grey Evaluation in Student Satisfaction Survey of University Service Product”, IEEE, 2012.

[9] Wang Li, Wang Changyao, Hao Penghu, Shi Kaifeng, Aablikim Abdullah, "Cotton Area Estimation using Multi-Sensor RS Data and Big Plot Survey in Xinjiang", IEEE, 2014.

[10] Pete Rotella, Sunita Chulani, "Analysis of Customer Satisfaction Survey Data", IEEE, 2010.

[11] Sharifah Nur Aina Syed Alwee, P. Hassan, H. Ramli and M. Maisham, "Bloom's taxonomy in the provision of quantity surveying degree programme," 2011 IEEE Symposium on Business, Engineering and Industrial Applications (ISBEIA), Langkawi, 2011, pp. 431-436.

[12] F. Hassan, Z. Ismail, A. A. Zaini, S. Hassan and M. Maisham, "An evaluation of the competencies, skills and knowledge of Quantity Surveying graduates in consultant Quantity Surveying firms in Malaysia," 2011 IEEE Colloquium on Humanities, Science and Engineering, Penang, 2011, pp. 228-232.

[13] J. Li and J. Xiong, "A Study of Sports and Leisure Tourism Behavior of Urban Residents Based on Web Survey," 2010 International Conference on E-Business and E-Government, Guangzhou, 2010, pp. 1998-2001.
[14] A. F. Zakaria and S. C. J. Lim, "A preliminary survey on modeling customer requirements from product reviews under preference uncertainty," 2014 IEEE International Conference on Industrial Engineering and Engineering Management, Bandar Sunway, 2014.

[15] C. Krueger, P. M. C. Swatman and K. van der Beek, "E-business models in the online music sector - a survey of 10 European countries," Proceedings of the Fourth International Conference onWeb Delivering of Music, 2004. EDELMUSIC 2004., Barcelona, Spain, 2004, pp. 156-165.

[16] M. F. Aniche and M. A. Gerosa, "Most Common Mistakes in Test-Driven Development Practice: Results from an Online Survey with Developers," 2010 Third International Conference on Software Testing, Verification, and Validation Workshops, Paris, 2010, pp. 469-478.

[17] J. D. Hastings, A. Mirasano, A. Latchininsky and S. P. Schell, "CARMA: Assessing Usability through a Non-Biased Online Survey Technique," 2010 43rd Hawaii International Conference on System Sciences, Honolulu, HI, 2010, pp. 1-10.

[18] K. L. Fancher and S. E. Breidenbach, "Spatial relationship surveys of navigation and surveying instrumentation of NOAA hydrographic ships and launches," Proceedings of OCEANS 2005 MTS/IEEE, Washington, DC, 2005, pp. 2396-2398, Vol. 3.

[19] D. E. Neumann and G. G. Glover, "Customer outreach using an authoritative hydrographic survey metadata database," Proceedings of OCEANS 2005 MTS/IEEE, Washington, DC, 2005, pp. 197-200, Vol. 1. 